\title{
Simulations of electric fields in planar dielectric waveguides
}

Frances Carter, John Foley, Ben Wyser, Matt Morris

Frances D. Carter, John T. Foley, Ben Wyser, Matt Morris, "Simulations of electric fields in planar dielectric waveguides," Proc. SPIE 9663, Eighth International Topical Meeting on Education and Training in Optics and Photonics, 966322 (6 October 2003); doi: 10.1117/12.2208488

SPIE Event: Eighth International Topical Meeting on Education and Training in Optics and Photonics, 2003, Tucson, Arizona, United States 


\title{
Simulations of Electric Fields in Planar Dielectric Waveguides
}

\author{
Frances D. Carter, John T. Foley, Ben Wyser, and Matt Morris \\ Department of Physics and Astronomy, Mississippi State University, P.O. Drawer 5167, Mississippi State, MS 39762 \\ Phone: 662-325-4112 Fax:662-325-8898,E-mail:fdc11@msstate.edu
}

Three-dimensional, animated electric field simulations of the transverse electric (TE) modes of a planar dielectric waveguide are presented. These waveguides guide light by total internal reflection and consist of a slab (the core) of dielectric material of refractive index $n_{l}$ and width $d$ surrounded by the cladding, a dielectric material with a lower refractive index $n_{2}$. The waveguide is symmetric in the $\mathrm{x}$-direction $(-d / 2 \leq x \leq d / 2)$ and the light propagates in the $\mathrm{y}$ direction (see the figure below). In the configuration considered, the electric field has only a z-component, which is plotted as a function of $x$ and $y$. The user chooses the mode number, $m$, of the mode that is displayed.

The analysis was performed by first determining the "bounce" angle, $\theta_{\mathrm{m}}$, for each mode by numerically solving the transcendental equation,

$$
\tan \left[\pi \frac{d}{\lambda_{1}} \sin \theta_{m}-m \frac{\pi}{2}\right]=\left(\frac{\sin ^{2} \bar{\theta}_{c}}{\sin ^{2} \theta_{m}}-1\right)^{\frac{1}{2}},
$$

where $\bar{\theta}_{c}$ is the complementary critical angle and $\lambda_{1}$ is the wavelength of the light in the core. ${ }^{1}$ The bounce angles are input into the wave function for the electric field of the mode, which satisfies Maxwell's equations and the relevant boundary conditions at the core/cladding interface. The wave functions were programmed using the Virtual Reality Modeling Language (VRML) and Java to produce the simulation, which runs inside a Web browser. The figure below depicts the electric field for the $m=2$ mode in a waveguide of thickness $2 \mu \mathrm{m}$. The free-space wavelength of the light is $0.87 \mu \mathrm{m}$ and the refractive indices of the core and cladding are 1.60 and 1.40 , respectively. The interactive simulation allows the user to change the wavelength, the refractive indices of the core and cladding, the mode number, and to observe the immediate effects of the changes on the electric field. This planar dielectric waveguide simulation is part of The Optics Project on the Web (WebTOP), a Web-based three-dimensional, interactive computer graphics system that simulates wave and optical phenomena. WebTOP may be accessed from http://webtop.msstate.edu.

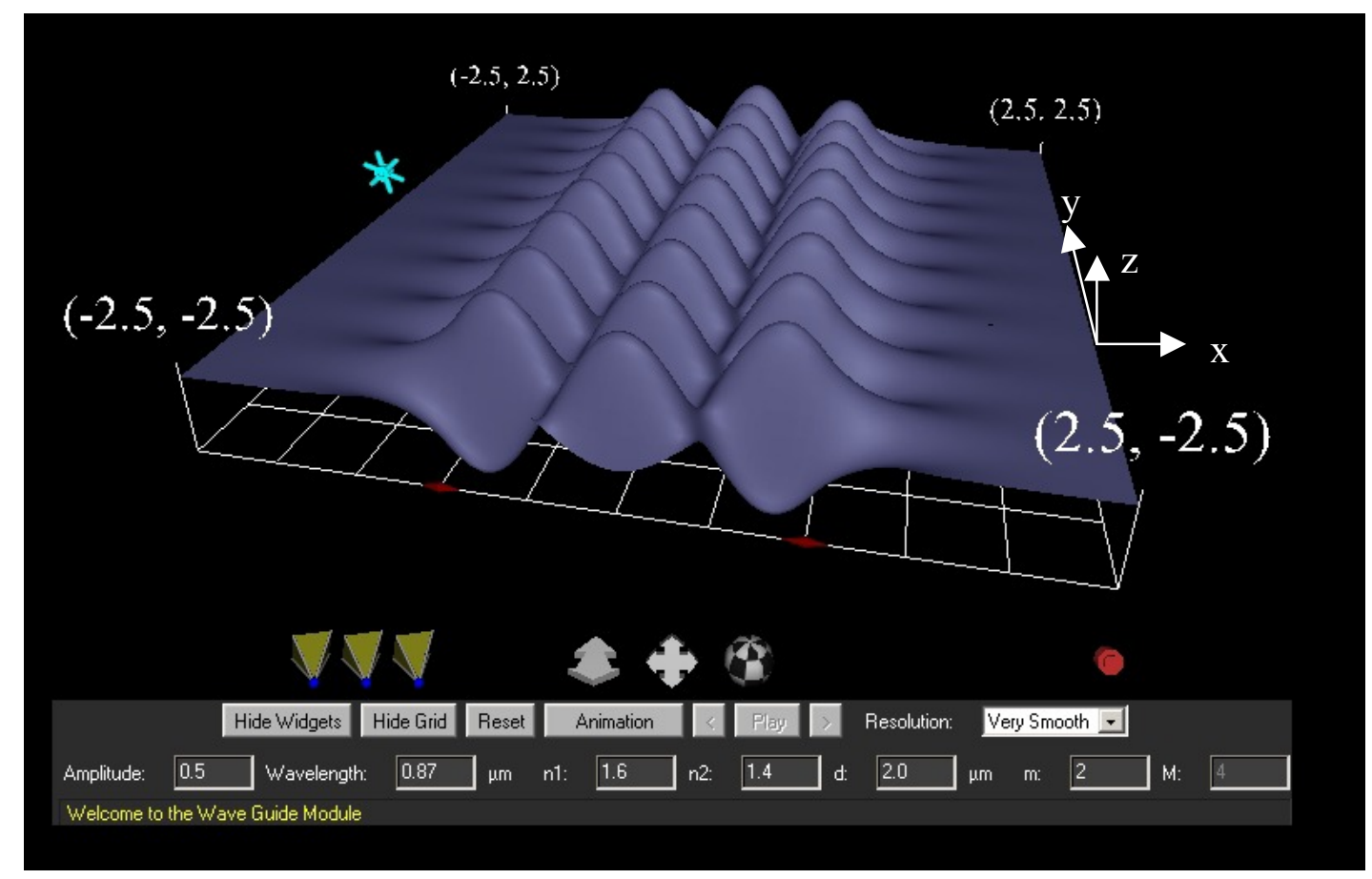

1. B.E.A. Saleh, M.C Teich, Fundamentals of Photonics (Wiley \& Sons, New York, NY, 1991).

Eighth International Topical Meeting on Education and Training in Optics and Photonics, edited by Barry L. Shoop, Grover Swartzlander Jr., Proc. of SPIE Vol. 9663, 966322

(C) 2003 SPIE, OSA, ICO - doi: 10.1117/12.2208488 